\section{Futebóis: apresentação}

Footballs: presentation

Havia um tempo em que falar de futebol era um tabu nas ciências sociais, a menos que fosse para falar mal. Embora seja possível localizar alguns trabalhos tomando o futebol a sério nas décadas de 1960 e 1970, é forçoso constatar que se tratavam de iniciativas isoladas. No Brasil, faz pouco mais de quarenta anos que surgiu a primeira dissertação tratando o futebol com a devida atenção. Desde então os trabalhos foram se multiplicando, em todos os formatos e nas mais diferentes áreas das ciências humanas, sociais e para além delas. Ao mesmo tempo em que essas investigações mantém um diálogo com as disciplinas de origem, também promoveram debates transversais de modo que não seria exagerado supor que tenhamos constituído, mesmo sem ter planejado, um campo de estudos esportivos no espectro do qual o futebol tem um destaque indiscutível.
Nos primórdios destacou-se a relação do futebol com a identidade nacional - uma questão tipicamente antropológica, que traduz o interesse precoce desta disciplina - e em seguida problematizaram-se as torcidas - organizadas ou não -, mais tarde os profissionais. Estes temas também foram permeados pelas narrativas de cronistas e pelos poetas. No entanto, quase sempre se tomou como objeto o futebol, no singular, o que na prática significava a sua versão espetacularizada e agenciada pelo Estado e/ou por entidades privadas vinculadas ao conglomerado FIFA. Negligenciou-se, quase sempre, as formas de praticar e torcer que escapassem a estes agenciamentos, visibilizados pela narrativa midiática, ela própria constitutiva desse cenário e comprometida com ele. A várzea, as peladas, o futebol de mulheres e dos povos indígenas, entre outros, permaneceram às margens.

Nas últimas décadas, finalmente, esta tendência de privilegiar o mainstream vem sendo revista, em favor de uma ampliação dos horizontes futebolísticos pesquisáveis a que corresponde uma atualização dos enfoques teóricos. 0 destacado interesse pelo futebol de mulheres ou mesmo pela participação das mulheres no universo do futebol é apenas um indício inequívoco das 
transformações em curso. No espectro dos estudos esportivos, um nome de ocasião para referir uma miríade multidisciplinar de abordagens que se entrelaçam e se tencionam mutuamente, o futebol tem um espaço cativo, especialmente no caso brasileiro em que ele de fato nunca foi apenas uma modalidade esportiva. Então não vem ao caso o fato de que sigamos falando mais de futebol, antes de que estamos empenhados em falar dele no plural, das formas até menos consagradas ou que estão sendo só agora visibilizadas. Por isso a ideia de futebóis, no plural; porque os modos de existência desse jogo simples e cativante são de fato diversificadas e os tais estudos esportivos precisam dar conta disso.

A par dessa tendência, a revista FuLiA / UFMG abriu espaço para um dossiê para tratar dos futebóis - não interessa tanto o termo, evidentemente, mas a concepção plural que ele sugere. Os textos que compõem o Dossiê da presente edição refletem esta tendência pluralista e são o prenúncio de que ela possa ser ampliada ainda mais. Afinal este dossiê não é um repositório de ideias ou relatos inertes de pesquisas, antes pensamentos em curso e, portanto, destinados a suscitar engajamentos, críticas e inovações.

\section{Em Festivais esportivos varzeanos em Belo Horizonte:} memória social da cultura futebolística popular, Raphael Rajão Ribeiro discute a realização de festivais esportivos pelos clubes de futebol de várzea de Belo Horizonte ao longo da segunda metade do século XX. Essa forma de celebração foi um dos elementos centrais da conformação do calendário das agremiações amadoras até os anos 1980, a partir de quando, progressivamente, foi entrando em desuso. Por meio da memória social construída acerca da festividade, o autor descreve as relações de reciprocidade entre os clubes de várzea e as formas rituais nela encerradas, buscando compreender os significados da cerimônia para a conformação e a renovação de laços entre os seus participantes. Vale ressaltar, tais festivais não incluíam apenas os jogadores, mas toda a comunidade. Para tanto, além de jogos envolvendo desde equipes de iniciantes eram recorrentes os concursos de beleza e a realização de bailes, fazendo justiça à designação de "festivais".

\section{Com o ensaio Futebóis - da horizontalidade epistemológica à}

diversidade política, de minha autoria, procuro recuperar o contexto no qual o conceito de "futebóis" foi forjado, além de seus usos possíveis no presente e no futuro dos estudos esportivos. 
Primeiramente, argumento que o conceito foi usado em um momento no qual a produção em ciências sociais sobre a temática esportiva encontrava-se em expansão, procurando se estabelecer enquanto um polo discursivo próprio, razão pela qual a noção de futebóis objetivava promover uma horizontalidade epistemológica, diferenciando o que deveria ser objeto de interesse das ciências sociais - todas as práticas futebolísticas, sem restrições - daquele atinente à mídia, restrita à versão espetacularizada. Atualmente nos encontramos noutro contexto, marcado pela contestação da proeminência androcêntrica e pela renovação do campo, sob diferentes aspectos. Se há duas décadas a noção de "futebóis" ajudou a perceber o amplo espectro de práticas futebolísticas pesquisáveis, nota-se no presente uma mobilização crítica no sentido de discutir as implicações políticas que perpassam a definição de temas e as formas de dialogar com certos movimentos políticos que defendem as práticas e valores não hegemônicos. Sugiro que esta mudança de perspectiva está em curso e tem a ver também com mudanças ocorridas no futebol de espetáculo, as quais contribuíram para afastá-lo das classes populares, razão principal pela qual o futebol tornou-se um tema legítimo no campo das ciências sociais brasileiras.

Elcio Loureiro Cornelsen contribui para o presente dossiê com o artigo Futebol como simulacro: Tipp-Kick, um jogo alemão, no qual constrói uma reflexão sobre um jogo em especial, o TippKick, criado na Alemanha, na década de 1920, como simulacro do futebol. Em termos teóricos, Cornelsen orienta-se pelas noções de "ludicidade”, “jogo” e "representação” propostas pelo historiador e linguista holandês Johan Huizinga, bem como pela noção de "simulacro", conforme definida pelo sociólogo francês Roger Caillois. Trata-se de uma contribuição instigante, que recupera dois dos mais antigos e consagrados trabalhos sobre o jogo, situados antes da primeira metade do século $\mathrm{XX}$, quando o movimento de esportivização e, sobretudo, o de espetacularização, ainda não haviam produzido os efeitos perceptíveis na atualidade. De qualquer sorte, Huizinga e Callois são clássicos, como bem destaca Cornelsen, e como tal vale a pena retomá-los de tempos em tempos.

Em Futebol dos futebóis: dissolvendo valências simbólicas de gênero e sexualidade por dentro do futebol, os autores Luiz 
Henrique Toledo e Wagner Xavier Camargo tratam o futebol como uma espécie de "índice canônico" para se pensar certas formas de sociabilidade na contemporaneidade. Isto se deve ao fato de o futebol ser hegemônico a partir de múltiplas projeções e experiências valorativas, políticas, estéticas e sensoriais. Em seus desdobramentos simbólicos, ele não apenas se expandiu territorialmente, como tem oferecido um conjunto de metáforas aos "modos de existência" de indivíduos e grupos. Partindo desta ideia de "hegemonia" do futebol, partilhada tanto pelo senso comum quanto pela academia, os autores sugerem que tais "modos" se materializam e se disseminam em "múltiplos futebóis" que alcançaram expressões politizadas e que podem ser explorados "de dentro" deste fenômeno global. Para tanto, trazem um caso ocorrido durante a Copa do Mundo da Rússia-2018 para discutir a sexualização de corpos no contexto futebolístico midiatizado, pensando o futebol pela relativização de seus modos simbólicos de impor suas regras e sociabilidade esportivas, tomadas tacitamente como universais.

Outra contribuição interessante é o artigo de Jean Carlo Ribeiro e Joyce Nancy da Silva Corrêa, Higienismo e os primórdios do

esporte: os casos do Acre e de Goiás, no qual os autores demonstram como o esporte se constituiu enquanto símbolo da modernidade, ainda nas primeiras décadas do século XX, mesmo em regiões mais afastadas dos grandes centros urbanos, como nos casos dos estados de Goiás e Acre. Manifestações esportivas seriam registradas a partir de 1907 (no Estado de Goiás) e de 1909 (no território do Acre), demonstrando o interesse das elites locais pelas práticas tidas como modernas, indutoras de transformações de hábitos e costumes tradicionais. Presentes também nesse processo eram as retóricas higienistas, eugênicas e nacionalistas, efeito de um novo modelo educacional que se deseja implementar à nação.

Por fim, o dossiê conta com o artigo 0 futebol amador em Ponta Grossa/PR: uma análise da dimensão simbólica e instituinte do ritual de preparação para os jogos do Mirante Esporte Clube, de Miguel Archanjo de Freitas Junior e Edilson de Oliveira. Partindo de uma investigação etnográfica, os autores procuram analisar a função simbólica e instituinte das ações que compõem o ritual de preparação dos jogadores do Mirante Esporte Clube, equipe de futebol amador da cidade de Ponta Grossa, localizada no estado do Paraná. Para além da dimensão simbólica e espiritual do ritual, foi possível identificar ao longo do campeonato 
amador, que as ações executadas pelos jogadores contribuíam para a estruturação das posições sociais no grupo e no campo futebolístico amador pontagrossense. Deste modo, os atos do rito futebolístico eram também atos de instituição, no sentido bourdieusiano, através dos quais alguém é notificado sobre a sua "nova" posição social.

Na seção Paralelas, Rodrigo Koch publica o artigo Indícios de uma euro-futebolização no Sul do Brasil, um contraponto interessante ao tema do dossiê, pois o destaque aqui recai sobre a futebolização da cultura juvenil e, mais especificamente, o gosto de adolescentes da Região das Hortênsias, especialmente de Canela/RS, por clubes de futebol europeus. Tomando como suporte a noção de flâneur, um dos quatro perfis de torcedores indicados por Richard Giulianotti, Koch incorpora ao debate outros teóricos da cena "pós-estruturalista", com destaque para Stuart Hall. 0 estudo utiliza metodologia quantitativa e qualitativa, com a realização de um questionário seguido de entrevistas com inspiração etnográfica. 0 objetivo é compreender como os jovens são levados a se identificar com clubes europeus, paralelamente ao interesse por clubes locais - no caso em questão, Grêmio e Internacional, os dois clubes da capital do Rio Grande do Sul.

Na seção Entrevista, em Os caminhos do futebol praticado por mulheres no Brasil: entrevista com Silvana Goellner, Gabriel Canuto Nogueira da Gama conversa com uma das pesquisadoras mais influentes sobre o futebol de mulheres no Brasil. A entrevista foi realizada durante o "II Simpósio Internacional Futebol, Linguagem, Artes, Cultura e Lazer", realizado em setembro de 2016, na cidade de Belo Horizonte. Como constatado por Gabriel, na abertura da entrevista, Silvana "transborda retidão", um predicado a que se poderiam acrescer muitos outros. A entrevista enfoca diferentes questões atinentes ao futebol de mulheres - futebol feminino, em termos socialmente consagrados - a começar pelas questões envolvendo o preconceito, que proibiu, estigmatizou, invisibilizou e ainda obstaculiza a promoção desse futebol. Como historiadora das práticas esportivas e corporais, Silvana trata, entre outros temas, da importância de resgatar a memória das mulheres no futebol, tarefa a qual os estudos esportivos têm uma dívida e uma enorme contribuição a dar. Também fala da importância de se lutar por políticas públicas voltadas a esse 
futebol, que é muito mais do que uma modalidade esportiva. Se dissemos desde sempre que o futebol é um meio de socialização dos meninos brasileiros, talvez seja a hora de pensar que o futebol de mulheres poderia ressocializá-los.

A seção Poética, dedicada às múltiplas possibilidades das abordagens artísticas do futebol e do mundo dos esportes, reúne nesta edição quatro crônicas de Braulio Tavares - parceiro de Lenine e Prêmio Jabuti de Literatura Infantil/2009 - publicadas anteriormente no Jornal da Paraíba: "Pelada e democracia", "O futebol segundo do Jairzinho", "O lateral-esquerdo suspeitoso" e "O barra-a-barra". Todas são ótimas e devem ser lidas, sobretudo por quem tem uma pelada inesquecível na sua biografia. Eu retornei à infância, lendo "O barra-a-barra”, porque me fez lembrar do "trave-a-trave", um tipo de jogo mais rústico do que a pelada - parece impossível, mas não é! - pois consiste em chutes - chutões, na verdade - de uma trave a outra e se pode jogar em dupla: de irmãos, primos ou amigos. É de tirar o fôlego e estirar os músculos; além de ser um ótimo calmante. Saber que Ariano Suassuna fora um perna-de-pau não chega a impressionar, porque seria demais exigir dele algo mais do que já nos legou. Mas saber que ele fez um gol "arretado", como se lê em "O lateral-esquerdo suspeitoso", com um chute que era só para espantar a bola da zona de perigo me fez lembrar da minha própria biografia futebolística. Ela teve início no exato instante em que meu colega Caju - Gilmar da Rosa era seu nome de batismo - acertou-me um chute que do contrário seria um gol, nos idos da 2 a série primária. Eu pensei em sair de campo para nunca mais voltar, porque ele tinha um "canhão" no pé e a "patada" ardeu à beça. E no entanto, como é próprio das virações rocambolescas do futebol, fui abraçado pelos colegas pelo estoicismo involuntário. Sem que o desejasse, mas jamais esquecesse, garanti um honroso 0 a 0 em pleno sol do meio-dia, naquele longínquo março de 1978. 0 gesto não fez de mim um herói, apenas alguém no mundo dos outros. E o que mais poderia esperar?

Contribuir na organização deste Dossiê, sugerido pelos editores da FuLiA / UFMG, foi um privilégio e um desafio. Na década de 1990, quando tiveram início as incursões mais sistemáticas das ciências sociais pelo universo do futebol, havia de nossa parte uma esperança própria de quem está iniciando um percurso e o vê promissor. Estávamos em vias de superar um longo período de ditadura e, ao menos no espectro da antropologia urbana 
brasileira, esbanjava-se otimismo em relação às organizações populares, seus estilos de vida, cosmologias e estratégias de luta cotidianas. Mostrar que negros e mulatos, aclamados nos estádios e na mídia, um dia foram execrados do futebol poderia ser um alento a indicar outras possibilidades de emancipação popular. Dizer que a presença nos estádios era uma forma de participação na vida pública era uma forma de alargar o espectro da política e do interesse nela por parte de grupos marginalizados. As formas efusivas de torcer, protagonizadas pelos grupos organizados, expressavam a alma de uma nação que só os estádios revelavam por inteiro.

Algumas dessas crenças foram sendo reformuladas, revistas, aperfeiçoadas ou mesmo abandonadas. A produção cresceu e já não comporta certos romantismos de outrora, embora não devamos nos desfazer do bebê com a água do banho. Nesse percurso nossa esperança na nação, emaranhada ou não ao futebol, chegou a ser até maior do que nos primórdios, embora esteja agora em stand-by. Em todo o caso, depois de um lance haverá outro, até que o apito final seja trilado. Ainda assim não será o fim, pois outro jogo haverá de ser iniciado e a seu término, outro campeonato, indefinidamente. Assim haverá de ser com as nossas investigações, espero. Só não vejo como voltar atrás em relação a um projeto de defesa do pluralismo e da diversidade. Por isso, salve(m) os futebóis.

A todas e a todos, boa leitura!

Porto Alegre, 21 de abril de 2019.

Arlei Sander Damo Instituto de Filosofia e Ciências Humanas Universidade Federal do Rio Grande do Sul/ PPG em Antropologia Social

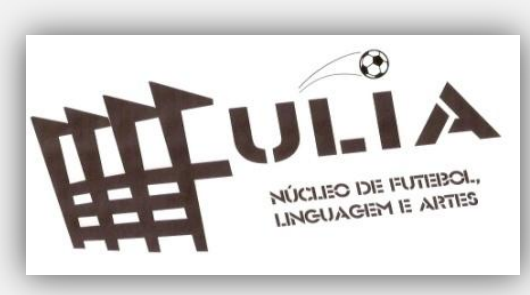

